\title{
Индивидуальный подход к физической подготовке на основе требований комплекса ГТО: андрагогический аспект
}

\author{
Воронков А.В., Исаев И.Ф., Никулин И.Н., Бражник Е.А. \\ Белгородский государственный национальный исследовательский университет \\ Россия, 308015, г. Белгород, ул. Победы, 85 \\ E-mail:voronkov@bsu.edu.ru; isaev@bsu.edu.ru; Nikulin_I@bsu.edu.ru; 1252927@bsu.edu.ru
}

\begin{abstract}
Аннотация. В настоящее время трудовая деятельность в большинстве профессий не связана с физической активностью, что ведет к развитию заболеваний сердечно-сосудистой системы, внутренних органов, опорно-двигательного аппарата. Целью исследования является обоснование индивидуализированной физической подготовки взрослых мужчин, основанной на требованиях комплекса ГТО. Представлены результаты экспериментальной работы по развитию основных физических качеств с учетом андрагогических особенностей организации тренировочного процесса. Экспериментальная методика предполагала ежедневные низко интенсивные самостоятельные занятия мужчин, продолжительность которых составляла 30 минут, и 35минутную аэробную нагрузку в виде ходьбы. Результаты исследования подтверждают достоверное улучшение показателей общей физической подготовленности мужчин 40-49 лет, участвующих в педагогическом эксперименте. Содержание занятий мужчин зрелого возраста физическими упражнениями должно иметь рекреативную направленность, предполагающую использование индивидуально привлекательных форм занятий, при условии получения удовольствия от самого процесса двигательной деятельности, свободы выбора, средств, методов, методических приемов, меры воздействия физических упражнений.
\end{abstract}

Ключевые слова: индивидуальный подход, физическая подготовка, андрагогика, мужчины зрелого возраста, комплекс ГТО.

Для цитирования: Воронков А.В., Исаев И.Ф., Никулин И.Н., Бражник Е.А. 2020. Индивидуальный подход к физической подготовке на основе требований комплекса ГТО: андрагогический аспект. Вопросы журналистики, педагогики, языкознания, 39 (4): 571-577. DOI $10.18413 / 2712-7451-2020-39-4-571-577$

\section{Individual approach to physical training based on the requirements of the GTO complex: andragogical aspect}

\author{
Alexander V. Voronkov, Ilya F. Isaev, Igor N. Nikulin, Ekaterina A. Brazhnik \\ Belgorod State University, \\ 85 Pobeda St, Belgorod, 308015, Russia \\ E-mail: voronkov@bsu.edu.ru; isaev@bsu.edu.ru; Nikulin_I@bsu.edu.ru; 1252927@bsu.edu.ru
}

\begin{abstract}
Annotation. Currently, work in most professions is not associated with physical activity, which leads to the development of diseases of the cardiovascular system, internal organs, and the musculoskeletal system. The purpose of the study is to substantiate individualized physical training of adult men based on the requirements of the GTO complex test. The article presents the results of experimental work on the development of basic physical qualities, taking into account the andragogical features of the organization of the training process. The experimental method assumed daily low-intensity independent exercises for men, the duration of which was 30 minutes and 25-35 minutes of aerobic exercise in the form of walking.
\end{abstract}


The peculiarity of the method is to perform tests of the GTO complex tests with low intensity based on an individual approach. The results of the study confirm a significant improvement in the overall physical fitness of men 40-49 years old participating in the pedagogical experiment. The content of physical exercises for men of mature age preferably should have a recreational orientation. This orientation is characterized by the use of individually attractive forms of training, getting pleasure from the process of motor activity, freedom of choice of means, methods, methodological techniques, measures of influence of physical exercises.

Keywords: individual approach, physical training, andragogy, men of mature age, GTO complex.

For citation: Voronkov A.V., Isaev I.F., Nikulin I.N., Brazhnik E.A. 2020. Individual approach to physical training based on the requirements of the GTO complex: andragogical aspect. Issues in Journalism, Education, Linguistics, 39 (4): 571-577 (in Russian). DOI 10.18413/2712-7451-2020-39-4$571-577$

\section{Введение}

Процесс целенаправленного физического воспитания традиционно осуществляется в различных образовательных учреждениях. Как правило, по окончании обучения в вузе, человек значительно снижает свою двигательную активность. В настоящее время трудовая деятельность в большинстве профессий не связана с физической активностью. Современный темп развития общества стимулирует человека на продолжение самообразования в течение всей жизни. Это необходимо для сохранения конкурентоспособности на рынке труда. При этом в большей степени востребованы умственные способности. Физическая подготовленность отходит на второй план, и физкультурное образование человека, как следствие, заканчивается. В связи с этим развиваются заболевания, вызванные низкой двигательной активностью. К ним специалисты относят многие заболевания сердечнососудистой системы, заболевания внутренних органов, опорно-двигательного аппарата [Амосов, Бендет, 1984; Купер, 1989; Мильнер, 1992].

С возрастом значение дозированной физической активности только повышается [Амосов, Бендет, 1984; Купер, 1989]. Возрастной период 40-60 лет у мужчин и 35-55 лет у женщин относится ко второму периоду зрелого возраста. Установлено, что после 35 лет постепенно проявляются процессы инволюции функциональных возможностей организма, заметно усиливающиеся после 40 лет [Курамшин, 2004]. По мнению специалистов [Амосов, Бендет, 1984; Воронков и др., 2007; Купер, 1989, Ирхин и др. 2020], эффективной формой поддержания физической активности могут являться самостоятельные занятия, проводимые в домашних условиях. Особую актуальность они приобретают в период пандемии, сопровождающейся рядом ограничений.

Отмечается, что самостоятельные занятия должны проводиться в полном соответствии с состоянием здоровья, степенью физического развития, полом занимающихся. Наиболее предпочтителен для лиц зрелого возраста рекреативный характер занятий физическими упражнениями [Назаренко, 2003; Воронков и др., 2007]. Рекреативная направленность занятий физической культурой предполагает использование индивидуально привлекательных физических упражнений, получение удовольствия от самого процесса двигательной деятельности. Содержание физкультурно-рекреативной деятельности определяется направленностью использования физических упражнений на улучшение психофизиологической работоспособности, развлечение и совершенствование личности, неформальное общение, переключение на двигательную активность, профилактику неблагоприятных воздействий окружающей среды [Воронков и др., 2007]. 
Методической основой для разработки методики самостоятельных занятий физическими упражнениями в любом возрасте могут служить не только рекомендации специалистов по физической культуре и организации здорового образа жизни, но и государственные требования Всероссийского физкультурно-спортивного комплекса «Готов к труду и обороне» [Федеральный портал ..., 2019].

Возрожденный в 2014 году указом президента Всероссийский физкультурноспортивный комплекс «Готов к труду и обороне» является программной и нормативной основой системы физического воспитания граждан Российской Федерации, устанавливающей государственные требования к уровню их физической подготовленности [О физической..., 2015].

Предполагается, что методика ежедневных низкоинтенсивных занятий физическими упражнениями, основанная на требованиях комплекса ГТО, позволит повысить уровень общей физической подготовленности мужчин 40-49 лет.

\section{Организация и методы исследования}

В рамках эксперимента реализовывалась методика физической подготовленности мужчин 40-49 лет, предполагающая самостоятельные физкультурные занятия на основе индивидуального подхода.

Основными требованиями для участия в эксперименте были следующее: 1) характер профессиональной деятельности мужчин не предполагал значительный объем двигательной активности; 2) мужчины до начала эксперимента не занимались целенаправленно никакими формами физкультурной активности. Комплекс упражнений разрабатывался участниками эксперимента самостоятельно.

Эксперимент длился с октября 2019 по март 2020 включительно. В нем приняли участие 8 мужчин 40-49 лет, возраст которых соответствовал восьмой ступени комплекса ГТО. В течение эксперимента все участники группы ежедневно выполняли индивидуальный комплекс упражнений в домашних условиях, продолжительность которого составляла не более 30 минут. Особенность данной методики в том, что использовались упражнения, которые являются испытаниями, рекомендуемыми комплексом ГТО для данной возрастной ступени. Большая часть этих упражнений развивают различных силовые способностей, а также оказывают оздоровительное воздействие на организм [Физиология..., 1982; Уилмор, Костил, 1997; Ингерлейб, 2008; Селуянов, 2009]. Кроме этого, не менее трех раз в неделю участники эксперимента в рамках «попутной тренировки» выполняли ходьбу продолжительностью 25-35 минут, добираясь на работу или с работы пешком. Ходьба выполнялась в быстром темпе для того, чтобы обеспечить воздействие на системы аэробного энергообеспечения организма [Купер, 1989]. Аэробные нагрузки низкой и средней интенсивности благоприятно сказываются ни только на развитии сердечно-сосудистой и дыхательной систем человека, но и способствуют снижению стресса и повышению умственной работоспособности [Смородинов, 1995; Вайнер, 2001; Собянин и др., 2011].

Индивидуальный подход при разработке методики предполагал учет рекомендаций Н.М. Амосова, Я.А. Бендета [1984], Ю.В. Менхина, А.В. Менхина [2002] и др. Учитывались нормативы, отраженные в комплексе ГТО [Государственные..., 2019]. В рамках эксперимента связь и консультации с участниками осуществлялась посредством социальных сетей. При этом особое внимание уделялось психоэмоциональному состоянию занимающихся, учитывалось настроение, желание заниматься, самочувствие до и после каждого занятия. Индивидуально подбирался объем и интенсивность нагрузки при выполнении упражнений на основе результатов предварительного тестирования физической подготовленности. 
Все тесты выполнялись в соответствии с методическими рекомендациями по организации и выполнению испытаний (тестов) Всероссийского физкультурно-спортивного комплекса «Готов к труду и обороне» [Методические..., 2018].

Полученные в ходе тестирования результаты подверглись математической обработке с целью определения достоверности различий по t-критерию Стьюдента. Достоверными считались различия на 5 \% уровня значимости.

\section{Результаты исследования}

С помощью тестирования до и после эксперимента была определенна физическая подготовленность всех участников эксперимента. В качестве тестов были использованы испытания, рекомендованные комплексом ГТО для данной возрастной ступени. Итоги математической обработки результатов отражены в таблице (см. таблицу).

Показатели тестирования участников до и после эксперимента

Testing indicators in the experimental group before and after experiment

\begin{tabular}{|l|c|c|c|c|}
\hline \multicolumn{1}{|c|}{$\begin{array}{c}\text { Виды контрольных } \\
\text { испытаний }\end{array}$} & $\begin{array}{c}\text { До } \\
\text { эксперимента } \\
\overline{\mathrm{X}} \pm \mathrm{m}\end{array}$ & $\begin{array}{c}\text { После } \\
\text { эксперимента } \\
\overline{\mathrm{X}} \pm \mathrm{m}\end{array}$ & $\mathrm{t}$ & $\mathrm{P}$ \\
\hline $\begin{array}{l}\text { Подтягивание из виса на высокой } \\
\text { перекладине (кол-во раз) }\end{array}$ & $3,4 \pm 1,2$ & $5,8^{* *} \pm 1,1$ & 2,4 & $<0,05$ \\
\hline $\begin{array}{l}\text { Подтягивание из виса лежа на низкой } \\
\text { перекладине (кол-во раз) }\end{array}$ & $7,5 \pm 1,1$ & $11,6^{* *} \pm 1,0$ & 2,8 & $<0,05$ \\
\hline $\begin{array}{l}\text { Сгибание-разгибание рук в упоре } \\
\text { лежа (кол-во раз) }\end{array}$ & $13,2^{*} \pm 1,7$ & $22,4 * * \pm 1,6$ & 3,2 & $<0,05$ \\
\hline Рывок гири 16 кг (кол-во раз) & $21^{* *} \pm 2,4$ & $29 * * * \pm 2,2$ & 2,9 & $<0,05$ \\
\hline $\begin{array}{l}\text { Поднимание туловища } \\
\text { из положения лежа на спине } \\
\text { (кол-во раз за 60 сек.) }\end{array}$ & $28^{* *} \pm 3,4$ & $39 * * * \pm 3,2$ & 3,1 & $<0,05$ \\
\hline $\begin{array}{l}\text { Наклон вперед из положения стоя } \\
\text { с прямыми ногами (см) }\end{array}$ & $+2^{*} \pm 1,4$ & $+9 * * * \pm 2,2$ & 3,2 & $<0,05$ \\
\hline Бег на 2 км (сек.) & $751^{*} \pm 34$ & $655^{* *} \pm 32$ & 2,8 & $<0,05$ \\
\hline
\end{tabular}

Примечания: * - соответствует бронзовому знаку отличия комплекса ГТО; ** - соответствует серебряному знаку отличия комплекса ГТО; *** - соответствует золотому знаку отличия комплекса ГТО.

Установлено, что по результатам предварительного тестирования средний показатель в некоторых упражнениях ниже норматива бронзового знака комплекса ГТО. К этим упражнениям относятся подтягивания из виса на высокой и низкой перекладине. В сгибаниях и разгибаниях рук в упоре лежа средний показатель соответствует бронзовому знаку. Наиболее легким из всех силовых испытаний для мужчин 40-49 лет оказался рывок гири весом 16 кг. Все участники эксперимента смогли выполнить хотя бы одно из силовых испытаний на знак отличия.

В испытании «поднимание туловища из положения лежа на спине» все участники эксперимента смогли показать результат, соответствующий одному из трех знаков комплекса ГТО. Средний показатель в этом упражнении в группе соответствовал серебряному знаку. В испытании на развитие выносливости «бег на 2 км» два человека из восьми не смогли выполнить норматив даже на бронзовый знак. В контрольном упражнении для оценки гибкости «наклон вперед из положения стоя с прямыми ногами» 50 \% испытуемых 
не смогли выполнить упражнение даже на бронзовый знак. Средний результат соответствовал бронзовому знаку.

При сравнении результатов итогового и предварительного тестирования отмечается значительный прирост во всех упражнениях. Средний результат в подтягиваниях у мужчин улучшился на 3,5 повторения, в подтягивании в висе лежа - на 4 повторения, в сгибании и разгибании рук в упоре лежа - на 9 повторений. В испытании «поднимание туловища из положения лежа» результат улучшился на 11 повторений. В испытании по определению гибкости «наклоне вперед из положения стоя» - на 7 см, что соответствует золотому знаку отличия комплекса ГТО. Таким образом, ежедневное выполнение упражнений на гибкость позволяет достоверно улучшить ее показатели в возрасте, который не является сенситивным периодом для развития данного качества.

В беге на 2 км результаты улучшились на 1,5 минуты. При этом прирост является достоверным на 5-процентном уровне значимости $(\mathrm{P}<0,05)$.

\section{Заключение}

Методика ежедневных низкоинтенсивных занятий физическими упражнениями, основанная на требованиях Всероссийского физкультурно-спортивного комплекса «Готов к труду и обороне», способствует достоверному повышению уровня общей физической подготовленности мужчин второго периода зрелого возраста (40-49 лет). Ежедневное выполнение упражнений на растягивание позволяет достоверно улучшить показатели гибкости в возрасте, который не является сенситивным периодом для развития данного качества. Регулярные (не менее 3-х раз в неделю), низкоинтенсивные аэробные упражнения позволяют достоверно повысить уровень общей выносливости мужчин 40-49 лет, профессиональная деятельность которых предполагает низкий объем двигательной активности. Большую эффективность показали физические упражнения силовой и скоростно-силовой направленности, выполняемые с весом собственного тела.

Самостоятельная форма проведения занятий, приобретая особую актуальность в период пандемии, позволяет заниматься физическими упражнениями с минимальными затратами времени и максимальной индивидуализацией тренировочного процесса. Содержание занятий мужчин 40-49 лет физическими упражнениями должно иметь предпочтительно рекреативную направленность, предполагающую использование индивидуально привлекательных форм занятий, при условии получения удовольствия от самого процесса двигательной деятельности, свободы выбора средств, методов, методических приемов, меры воздействия физических упражнений.

\section{Список источников}

1. Государственные требования Всероссийского физкультурно-спортивного комплекса «Готов к труду и обороне» (ГТО): утверждены приказом Минспорта России от 12.02.2019 № 90. Федеральный портал «GTO.RU». $2019 . \quad$ URL: https://www.gto.ru/files/uploads /documents/5c8a217b493d3.pdf_(дата обращения: 04.10.2020).

2. Методические рекомендации по организации физкультурных мероприятий и спортивных мероприятий Всероссийского физкультурно-спортивного комплекса «Готов к труду и обороне» (ГТО)»: утверждены Министром спорта Российской Федерации 01.02.2018. Федеральный портал «GTO.RU». URL: https://www.gto.ru/files/uploads/documents 15ac34cb02362e.pdf (дата обращения: 04.10.2020).

3. О физической культуре и спорте в Российской Федерации: федер. закон от 04.12.2007 № 329-Ф3 (ред. от 29 июня 2015). Федеральный портал «GTO.RU». URL: http://www.gto.ru/files /uploads/documents /56ea7831a51cd.pdf

4. Вайнер Э.Н. 2001. Валеология. М., Флинта, Наука, 416 с. 
5. Ингерлейб М.Б. 2008. Анатомия физических упражнений: лечебный эффект в каждом движении. Ростов н/Д, Феникс, 187 с.

6. Купер К. 1989. Аэробика для хорошего самочувствия. М., Физкультура и спорт, 225 с.

7. Менхин Ю.В., Менхин А.В. 2002. Оздоровительная гимнастика: теория и методика. Ростов н/Д, Феникс, 384 с.

8. Мильнер Е.Г. 1992. Формула жизни: медико-биологические основы оздоровительной физической культуры. М., Физкультура и спорт, 112 с.

9. Назаренко Л.Д. 2003. Оздоровительные основы физических упражнений. М., Изд-во ВЛАДОС-ПРЕСС, $240 \mathrm{c.}$

10.Селуянов В.Н. 2009. Технология оздоровительной физической культуры. М., ТВТ Дивизион, 192 с.

11.Смородинов А.С. 1995. Физическая культура в режиме дня работников умственного труда. Воронеж, ВГЛТА, 85 с.

12.Теория и методика физической культуры. 2004. Под ред. Ю.Ф. Курамшина. М., Советский спорт, $463 \mathrm{c}$.

13.Уилмор Дж.Х., Костилл Д.Л. 1997. Физиология спорта и двигательной активности. Киев, Олимпийская литература, 503 с.

14.Физиология мышечной деятельности. 1982. Под ред. Я.М. Коца. М., Физкультура и спорт, $347 \mathrm{c}$.

15. Хоули Эд.Т., Френкс Б.Д. 2000. Оздоровительный фитнес. Пер. с англ. А. Ященко. Киев, Олимпийская литература, 368 с.

\section{Список литературы}

1. Амосов Н.М., Бендет Я.А. 1984. Физическая активность и сердце. Киев, Здоров'я, 234 с.

2. Воронков А.В. 2007. Педагогические условия организации физкультурно-рекреативной деятельности в учительском коллективе. Дис. ... канд. пед. наук. Белгород, 202 с.

3. Воронков А.В., Исаев И.Ф., Никулин И.Н. 2007. Физкультурно-рекреативная деятельность в педагогическом коллективе школы. Теория и практика физической культуры, 9: 26-29.

4. Ирхин В.Н., Ирхина И.В., Остапенко С.И., Пахомова Л.Э. 2020. Алгоритмический подход в системе физкультурного образования. Теория и практика физической культуры, 7: 104-106.

5. Собянин Ф.И., Бочарова В.И., Куликов И.А. 2011. Выявление эффективных средств физической культуры, способствующих повышению умственной работоспособности студентов вузов. Культура физическая и здоровье, 11: 29-32.

\section{References}

1. Amosov N.M., Bendet Ya.A. 1984. Fizicheskaya aktivnost' i serdtse [Physical Activity and the Heart]. Kiev, Publ. Zdorov'ya, 234 p.

2. Voronkov A.V. 2007. Pedagogicheskie usloviya organizatsii fizkul'turno-rekreativnoy deyatel'nosti v uchitel'skom kollektive [Pedagogical conditions for the organization of physical culture and recreational activities in the teaching staff]. Dis. ... cand. ped. sciences. Belgorod, $202 \mathrm{p}$.

3. Voronkov A.V., Isaev I.F., Nikulin I.N. 2007. Fizkul'turno-rekreativnaya deyatel'nost' v pedagogicheskom kollektive shkoly [Physical culture and recreational activities in the teaching staff of the school]. Teoriya i practika fizicheskoy kultury, 9: 26-29.

4. Irkhin V.N., Irkhina I.V., Ostapenko S.I., Pakhomova L.E. 2020. Algoritmicheskiy podkhod v sisteme fizkul'turnogo obrazovaniya [Algorithmic approach in the system of physical education]. Teoriya i practika fizicheskoy kultury, 7: 104-106.

5. Sobyanin F.I., Bocharova V.I., Kulikov I.A. 2011. Vyyavlenie effektivnykh sredstv fizicheskoy kul'tury, sposobstvuyushchikh povysheniyu umstvennoy rabotosposobnosti studentov vuzov [Revealing of effective means of physical culture, contributing to the increase of mental performance of university students]. Physical culture and healt, 11: 29-32. 


\section{ИНФОРМАЦИЯ ОБ АВТОРАХ}

Воронков Александр Владимирович, кандидат педагогических наук, доцент, заведующий кафедрой спортивных дисциплин, Белгородский государственный национальный исследовательский университет, г. Белгород, Россия

Исаев Илья Федорович, доктор педагогических наук, профессор, профессор кафедры педагогики, Белгородский государственный национальный исследовательский университет, г. Белгород, Россия

Никулин Игорь Николаевич, кандидат педагогических наук, доцент, декан факультета физической культуры, Белгородский государственный национальный исследовательский университет, г. Белгород, Россия

Бражник Екатерина Андреевна, студент факультета физической культуры, Белгородский государственный национальный исследовательский университет, г. Белгород, Россия

\section{INFORMATION ABOUT THE AUTHORS}

Alexander V. Voronkov, Candidate of Pedagogical Sciences, Associate Professor, Head of the Department of Sports Disciplines, Belgorod State National Research University, Belgorod, Russia

Ilya F. Isaev, Doctor of Pedagogy, Professor, Professor of the Department of Pedagogy, Belgorod State National Research University, Belgorod, Russia

Igor N. Nikulin, Candidate of Pedagogy, Associate Professor, Dean of the Faculty of Physical Education, Belgorod State National Research University, Belgorod, Russia

Ekaterina A. Brazhnik, student of the Faculty of Physical Education, Belgorod State National Research University, Belgorod, Russia 